\title{
Physiological Character of Merremia peltata (L.) Merrill from Bukit Barisan Selatan National Park Lampung
}

\author{
Yuke Mardiati ${ }^{1}$, Triadiati Triadiati ${ }^{2 *}$, Soekisman Tjitrosoedirdjo ${ }^{3}$ \\ 'Study Program of Plant Biology, Postgraduate School, Bogor Agricultural University, Bogor, Indonesia \\ ${ }^{2}$ Department of Biology, Faculty of Mathematics and Natural Sciences, Bogor Agricultural University, Bogor, Indonesia \\ ${ }^{3}$ Weed Science Society of Indonesia, BIOTROP, Bogor, Indonesia
}

ARTICLE INFO

\section{Article history:}

Received April 16, 2017

Received in revised form January 4, 2018

Accepted January 11, 2018

\section{KEYWORDS:}

Merremia peltata,

invasive plant,

carbon fixation rate,

relative growth rate

\begin{abstract}
Merremia peltata invaded the vegetation of Bukit Barisan Selatan National Park (BBSNP) in Lampung Province, Indonesia. In this site, the invasion has reached more than $\mathbf{7 0 0 0}$ hectares. Therefore, it is necessary to asses the physiological characters of $M$. peltata as an invasive plant species under different shading level in BBSNP. The experiment design of this study was split block design with factorial. The first factor (main plot) was shading treatment that consisted of 0,55 , and $90 \%$ shades. The second factor (sub plot) was 3 species of plant that consisted of M. peltata, Mikania micrantha, and Ipomoea batatas. Each experimental unit was replicated 3 times. The result showed that the physiological characters such as carbon fixation rate (CFR), relative growth rate (RGR), leaf area ratio (LAR), photosynthetics nitrogen use efficiency (PNUE) of $M$. peltata higher than the other two species and interconnected. Physiological characters associated with RGR can be supporting the invasiveness of $M$. peltata, especially in BBSNP. Supporting invasiveness with resources allocation to leaves biosynthesis and relatively efficient nitrogen were used for photosynthesis.
\end{abstract}

\section{Introduction}

Merremia peltata (Convolvulaceae) locally known as mantangan invaded Bukit Barisan Selatan National Park (BBSNP), Lampung Province, Indonesia covering an area more than 7000 ha. This vast invasion impacted BBSNP considerably hindering natural regeneration (Master et al. 2013) and driving elephants to migrate northward creating conflict of interest with human settlement (Irianto and Tjitrosoedirdjo 2010). Some physiological characters of $M$. peltata that may support its invasiveness compared with Mikania micrantha, a species with known physiological characters admited as being invasive (Deng et al. 2004) and a non invasive crop, Ipomoea batatas. Knowledge and understanding of plant invasion mechanism are an important information for managing invasive plant species. In most cases of plant invasions were usually associated with lack of natural enemies of the invading species, although $M$. peltata is implicated as a native species to Indonesia, so far no natural enemies being reported attacking the plant. Irianto and Tjitrosoedirdjo (2010) speculated that the invasiveness of $M$. peltata may be atributed to changes in its environment into a more open one,

\footnotetext{
* Corresponding Author.

E-mail Address: adiatiipb@gmail.com
}

facilitating a greater availability of light and therefore supporting its fast growth. The domination of invasive plants is usually indicated by fast growing, expansive dispersion, and efficient resources use (Matzek 2011). The invasive nature of $M$. peltata is hypothesized due to some physiological characteristics. In order to identity the M. peltata's physiological characteristics some of its physiological characters were compared with $M$. micrantha which was known as an invasive plants (Deng et al. 2004) and I. batatas which belongs to non-invasive cultivated plants (Tjitrosoedidjo 2010). The area was known as a degraded forest leaving only a meager trees (Master et al. 2013).

The hypotesis of this study was the M. peltata growth which was thought as an invasive species affected by shade. Therefore, the objective of the research was physiological characters of M. peltata from BBSNP as an invasive plant species under different shading level which support them to invade a certain ecosystem.

\section{Materials and Methods}

\subsection{Materials}

M. peltata (from BBSNP in Pemerihan Village, West Lampung Regency), M. micrantha, and I. batatas were used in this research. Soil and compost manures fertilizer with 3:2 (w/w) were used as planting media. 


\subsection{Experimental Design}

This research was carried out at the green house and field experiment. Experiment design was a split block design with factorials. The first factor (main plot) was shading treatment by using shade net of 0 , 55 , and $90 \%$ shades. The second factor (sub plot) was 3 species of plant i.e. M. peltata, M. micrantha, and I. batatas). Each experimental unit was replicated 3 times.

Observed variables were carbon fixation rate (CFR), relative growth rate (RGR), leaf weight ratio (LWR), specific leaf area (SLA), leaf area ratio (LAR), net assimilation rate (NAR), leaf nitrogen, and photosynthetics nitrogen use efficiency (PNUE).

\subsection{Plant Propagation}

$M$. peltata was tried to be grown using stem cutting, but failed to grow and subsequently $M$. peltata was grown from seeds. Seeds were separated from the fruit capsules (brown, dry, chapped). The good quality of seeds (not rotten) were germinated in soil from BBSNP. Seeds were planted in the planting medium and covered with soil. Two weeks old seedlings were transferred into transparent plastic that containing soil from BBSNP. Seedlings of $M$. peltata were transferred to polybag planting medium. The thirty centimeters height seedlings were planted in planting media. The experiment was conducted using polybag (black colour and in size $25 \mathrm{~cm} \times 25 \mathrm{~cm}$ ), with $25 \mathrm{~cm}$ diameter and 20 $\mathrm{cm}$ height of planting medium with Cikabayan soil (were dug to $20 \mathrm{~cm}$ depth).

M. micrantha were propagated by using stem cuttings. The stem cuttings were used in $15 \mathrm{~cm}$ length and consisting of 3 leaves. Then, seedlings was adapted until 3 weeks period in the planting medium.

I. batatas were propagated by using stem cutting. The stem cuttings were used in $30 \mathrm{~cm}$ of length. These seedlings were planted by immersing 3-4 segments to the planting medium $(3: 2 \mathrm{w} / \mathrm{w})$. Then, the seedlings was adapted until 3 weeks period in planting medium.

\subsection{Measuring of CFR}

The CFR was measured by using portable photosynthesis system (Li-qor $6400 \quad \mathrm{xt}$ ). Measurement was used Photosynthetics Active Radiation (PAR) of $2000 \mu \mathrm{mol}$ photons $\mathrm{m}^{-2} \mathrm{~s}^{-1}$. Measurement was performed on the full width of the leaf (in the position of fifth to seventh leaves from the tip of the stem).

\subsection{Plant Growth Analysis}

Plants were harvested on 0 days after treatment and 90 days after treatment. Dry biomass of leaves, roots, stems and tubers were oven dried at $80^{\circ} \mathrm{C}$ until dry weight conctant. Leaf area was determined by gravimetric method. Parameters of growth analysis observed were: $R G R=\ln W_{1}-\ln W_{0} /(T 1-T 0) ; L W R=$
LW / DM; SLA = LA / LW; LAR = LWR x SLA; and NAR = RGR / LAR in this research. Where, $W$ is the dry weight of plants, T is time, LW is leaf dry weight, DM is dry weight of plant, and LA is the leaf area (Rodosevich et al. 1997). Nitrogen content was analyzed by using Kjeldahl method. Nitrogen was measured as nitrogen content per leaf area unit. PNUE was ratio between CFR with leaf nitrogen content.

\subsection{Data Analysis}

Data were analysed using analysis of Variance (ANOVA) and followed by Duncan's Multiple Range Test (DMRT) with confidence test level of 95\%. The relationship among variables was tested by using correlation (Pearson correlation $=r$ ). The grouping (based on the degree of similarity) of M. peltata with M. micrantha and I. batatas was tested by cluster analysis. Data analysis was processed by using SPSS v 16.0 program.

\section{Results}

\subsection{Carbon Fixation Rate}

Shading intracts with plant species significantly in affecting Carbon Fixation Rates (CFR). CFR of $M$. peltata $\left(19.0 \mu \mathrm{mol} \mathrm{CO} \mathrm{m}^{-2} \mathrm{~s}^{-1}\right)$ lower than CFR of $M$. micrantha $\left(25.2 \mu \mathrm{mol} \mathrm{CO} \mathrm{m}^{-2} \mathrm{~s}^{-1}\right)$, however, it was still the higher than CFR of I. batatas (Table 1). The reduction CFR of $M$. micrantha was about $14.7 \%$ under 55\% shade, and down to $55.5 \%$ under $90 \%$ shade, while that of $M$. peltata was $23.8 \%$ and $43.2 \%$ respectively. That of $I$. batatas was $19.0 \%$ and $81.0 \%$ respectively. Shading of $90 \%$ intensity created low light condition leading to plant death.

\subsection{Plant Growth}

All plant growth variables were showed significantly correlation (Table 2 ). The correlation between RGR with NAR $(r=0.711, P<0.05)$, RGR with LAR $(r=-0.229, P>0.05)$, LAR with LWR $(r=0.701, P$ $<0.05)$, LAR with SLA $(r=0.674, P<0.05)$, RGR with leaf nitrogen content $(r=0.733, P<0.05)$, and RGR with PNUE $(r=0.946, \mathrm{P}<0.05)$ were significantly different. These results significantly affected to plant growth.

Relative growth rate of $M$. peltata is slightly lower than that of M. micrantha but higher than that of $I$. batatas (Table 3 ). $\mathrm{RGR}_{\text {M.peltata }}=12=9.0 \times 1.4<\mathrm{RGR}_{\mathrm{M}}$. micrantha $=13=6.4 \times 2.1$. $\mathrm{LAR}_{\text {M. peltata }}$ (under $0 \%$ shade, 9 $\mathrm{cm}^{2} \mathrm{~g}^{-1}$ ) contributed more to the RGR of $M$. peltata if compare to LAR M. micrantha (under $0 \%$ shade, $6.4 \mathrm{~cm}^{2}$ $\mathrm{g}^{-1}$ ). On the other side, $M$. micrantha was contributed more by $\operatorname{NAR}_{\text {M. micrantha }}\left(2.1 \mathrm{mg} \mathrm{cm}^{-2}\right.$ day $\left.^{-1}\right)$ if compare to $\mathrm{NAR}_{\text {M. peltata }}$ (Table 3).

M. micrantha reached high content of leaf nitrogen and PNUE especially in shade net of $0 \%$ and 55\% (Table 4). Leaf nitrogen content of M. micrantha was the highest in $90 \%$ shade net $\left(118.0 \mathrm{~g} \mathrm{~m}^{-2}\right)$, but PNUE 
Table 1. CFR of M. peltata, M. micrantha, and I. batatas in shade net level treatments

\begin{tabular}{llc}
\hline $\begin{array}{l}\text { Shade Net } \\
\text { Treatment }\end{array}$ & Plant Species & $\begin{array}{c}\mathrm{CFR} \\
\left(\mu \mathrm{mol} \mathrm{CO} \mathrm{m}^{-2} \mathrm{~s}^{-1}\right)\end{array}$ \\
\hline Shade net 0\% & M. peltata & $19.0^{\mathrm{c}}$ \\
& M. micrantha & $25.2^{\mathrm{a}}$ \\
& I. batatas & $14.7^{\mathrm{d}}$ \\
Shade net 55\% & M. peltata & $14.5^{\mathrm{d}}$ \\
& M. micrantha & $21.5^{\mathrm{b}}$ \\
& I. batatas & $11.9^{\mathrm{e}}$ \\
Shade net 55\% & M. peltata & $10.8^{\mathrm{e}}$ \\
& M. micrantha & $11.2^{\mathrm{e}}$ \\
& I. batatas & $2.8^{\mathrm{f}}$ \\
\hline
\end{tabular}

Data with the same letter in the same column is not differ significantly at $\alpha=0.05$ (DMRT test)

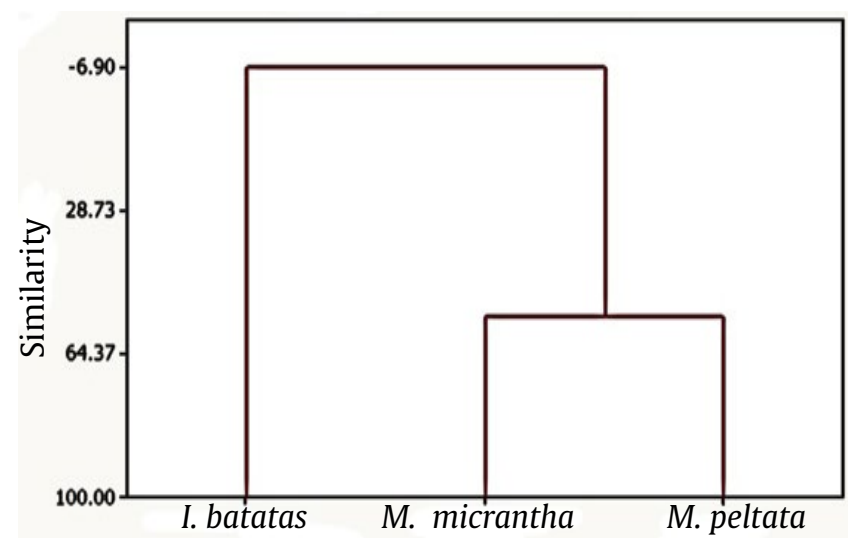

Figure 1. Dendrogram of the degree of similarity between M. peltata, M. micrantha, and I. batatas

Table 2. Correlation of carbon fixation rate and plant growth variables

\begin{tabular}{|c|c|c|c|c|c|c|c|c|}
\hline & CFR & RGR & LWR & SLA & LAR & NAR & $\begin{array}{c}\text { Leaves } \\
\text { nitrogen }\end{array}$ & PNUE \\
\hline$\overline{C F R}$ & 1 & & & & & & & \\
\hline RGR & 0.856 ** & 1 & & & & & & \\
\hline LWR & 0.211 & $0.388^{*}$ & 1 & & & & & \\
\hline SLA & $-0.823^{* *}$ & $-0.725^{* *}$ & -0.033 & 1 & & & & \\
\hline LAR & $-0.442^{*}$ & -0.229 & $0.701^{* *}$ & $0.674^{*}$ & 1 & & & \\
\hline NAR & $0.763^{*}$ & $0.711^{* *}$ & -0.322 & $-0.776^{* *}$ & $-0.779 * *$ & 1 & & \\
\hline $\begin{array}{l}\text { Leaf } \\
\text { nitrogen }\end{array}$ & $0.954^{* *}$ & $0.733^{* *}$ & 0.192 & $-0.869^{* *}$ & $-0.489^{* *}$ & $0.698^{* *}$ & 1 & \\
\hline PNUE & $0.875^{* *}$ & $0.946^{* *}$ & 0.298 & $-0.775^{* *}$ & -0.310 & $0.712^{* *}$ & $0.744^{* *}$ & 1 \\
\hline
\end{tabular}

Note : ${ }^{*}=$ significant at $\alpha=0.05,{ }^{* *}=$ significant at $\alpha=0.01$

Table 3. Plant growth analysis in shade net level and plant species treatments

\begin{tabular}{|c|c|c|c|c|c|c|}
\hline $\begin{array}{l}\text { Shade Net } \\
\text { Treatment }\end{array}$ & Plant Species & $\begin{array}{c}\text { RGR } \\
\left(\mathrm{mg} \mathrm{g}^{-1} \text { day }^{-1}\right)\end{array}$ & $\begin{array}{c}\text { LWR } \\
\left(\mathrm{mg} \mathrm{g}^{-1}\right)\end{array}$ & $\begin{array}{c}\text { SLA } \\
\left(\mathrm{cm}^{2} \mathrm{~g}^{-1}\right)\end{array}$ & $\begin{array}{c}\text { LAR } \\
\left(\mathrm{cm}^{2} \mathrm{~g}^{-1}\right)\end{array}$ & $\begin{array}{c}\text { NAR } \\
\left(\mathrm{mg} \mathrm{cm}^{-2} \mathrm{day}^{-1}\right)\end{array}$ \\
\hline Shade net $0 \%$ & $\begin{array}{l}\text { M. peltata } \\
\text { M. micrantha } \\
\text { I. batatas }\end{array}$ & $\begin{array}{l}12^{\mathrm{b}} \\
13^{\mathrm{a}} \\
11^{\mathrm{c}}\end{array}$ & $\begin{array}{l}300^{\mathrm{c}} \\
240^{\mathrm{d}} \\
350^{\mathrm{b}}\end{array}$ & $\begin{array}{l}30.1^{\mathrm{f}} \\
26.4^{\mathrm{g}} \\
42.0^{\mathrm{c}}\end{array}$ & $\begin{array}{r}9.0^{\mathrm{d}} \\
6.4^{\mathrm{ef}} \\
14.7^{\mathrm{b}}\end{array}$ & $\begin{array}{l}1.4^{\mathrm{d}} \\
2.1^{\mathrm{a}} \\
0.8^{\mathrm{f}}\end{array}$ \\
\hline Shade net 55\% & $\begin{array}{l}\text { M. peltata } \\
\text { M. micrantha } \\
\text { I. batatas }\end{array}$ & $\begin{array}{l}11^{\mathrm{c}} \\
12^{\mathrm{b}} \\
10^{\mathrm{c}}\end{array}$ & $\begin{array}{l}290^{\mathrm{c}} \\
220^{\mathrm{d}} \\
370^{\mathrm{a}}\end{array}$ & $\begin{array}{l}41.4^{\mathrm{c}} \\
36.1^{\mathrm{de}} \\
52.8^{\mathrm{b}}\end{array}$ & $\begin{array}{r}12.0^{\mathrm{c}} \\
8.1^{\mathrm{d}} \\
19.6^{\mathrm{a}}\end{array}$ & $\begin{array}{l}0.9^{e} \\
1.5^{c} \\
0.5^{g}\end{array}$ \\
\hline Shade net $90 \%$ & $\begin{array}{l}\text { M. peltata } \\
\text { M. micrantha } \\
\text { I. batatas }\end{array}$ & $\begin{array}{r}10^{\mathrm{c}} \\
5^{\mathrm{d}} \\
3^{\mathrm{e}}\end{array}$ & $\begin{array}{l}150^{\mathrm{f}} \\
200^{\mathrm{e}} \\
200^{\mathrm{e}}\end{array}$ & $\begin{array}{l}38.8^{\mathrm{cd}} \\
34.8^{\mathrm{e}} \\
76.4^{\mathrm{a}}\end{array}$ & $\begin{array}{r}5.7^{\mathrm{f}} \\
6.8^{\mathrm{e}} \\
14.8^{\mathrm{b}}\end{array}$ & $\begin{array}{l}1.8^{\mathrm{b}} \\
0.8^{\mathrm{f}} \\
0.2^{\mathrm{h}}\end{array}$ \\
\hline
\end{tabular}

Data with the same letter in the same column is not differ significantly at $\alpha=0.05$ (DMRT test)

Table 4. Leaves nitrogen in shade net level and species of plant treatments

\begin{tabular}{llcc}
\hline $\begin{array}{l}\text { Shade Net } \\
\text { Treatment }\end{array}$ & Plant Species & $\begin{array}{c}\text { Leaf Nitrogen } \\
\left(\mathrm{g} \mathrm{m}^{-2}\right)\end{array}$ & $\begin{array}{c}\text { PNUE } \\
\left(\mu \mathrm{mol} \mathrm{CO}_{2} \mathrm{~g}^{-1} \mathrm{~N} \mathrm{~s}^{-1}\right)\end{array}$ \\
\hline Shade net 0\% & M. peltata & $137.5^{\mathrm{b}}$ & $0.14^{\mathrm{bc}}$ \\
& M. micrantha & $171.1^{\mathrm{a}}$ & $0.15^{\mathrm{ab}}$ \\
& I. batatas & $119.2^{\mathrm{c}}$ & $0.12^{\mathrm{d}}$ \\
Shade net 55\% & M. peltata & $112.0^{\mathrm{c}}$ & $0.13^{\mathrm{cd}}$ \\
& M. micrantha & $138.8^{\mathrm{b}}$ & $0.16^{\mathrm{a}}$ \\
& I. batatas & $95.6^{\mathrm{d}}$ & $0.12^{\mathrm{d}}$ \\
Shade net 90\% & M. peltata & $89.4^{\mathrm{d}}$ & $0.12^{\mathrm{d}}$ \\
& M. micrantha & $118.0^{\mathrm{c}}$ & $0.09^{\mathrm{e}}$ \\
& I. batatas & $53.0^{\mathrm{e}}$ & $0.05^{\mathrm{f}}$ \\
\hline
\end{tabular}

Data with the same letter in the same column is not differ significantly at $\alpha=0.05$ (DMRT test) 
PNUE $_{\text {M. micrantha }}\left(0.09 \mu \mathrm{mol} \mathrm{CO}_{2} \mathrm{~g}^{-1} \mathrm{~N} \mathrm{~s}^{-1}\right)$ was lower that of PNUE ${ }_{\text {M. peltata }}\left(0.12 \mu \mathrm{mol} \mathrm{CO} \mathrm{g}^{-1} \mathrm{~N} \mathrm{~s}^{-1}\right)$. PNUE ${ }_{\text {M. peltata }}$ was relative stable in all level shade net, that were $0.14 \mu \mathrm{mol} \mathrm{CO} \mathrm{g}^{-1} \mathrm{~N} \mathrm{~s}^{-1}$ (in shade net of $0 \%$ ), $0.13 \mu \mathrm{mol}$ $\mathrm{CO}_{2} \mathrm{~g}^{-1} \mathrm{~N} \mathrm{~s}^{-1}$ (in shade net of 55\%), and $0.12 \mu \mathrm{mol} \mathrm{CO}_{2}$ $\mathrm{g}^{-1} \mathrm{~N} \mathrm{~s}^{-1}$ (in shade net of $90 \%$ ), respectively.

Based on all parameters of physiological, the degree of similarity between $M$. peltata with $M$. micrantha was $55 \%$, whereas, the degree of similarity between M. peltata with I. batatas was $-6.90 \%$ (Figure 1).

\section{Discussion}

Carbon fixation rate (CFR) of M. peltata under full sunlight ( $0 \%$ shade) was slightly lower than that of M. micrantha. When under 55\% shade, the reduction of CFR on M. peltata was higher than M. micrantha, however the reduction was somehow greater on $M$. micrantha under $90 \%$ coverage. The condition actually reduced the growth considerably and tended to kill the plants (Taiz and Zeiger 2010).

CFR of M. peltata in shade of $0 \%$ were higher than in other shading level. $M$. peltata still showed the ability to bind $\mathrm{CO}_{2}$ high enough, although grown in conditions of light exposure. In this case, M. peltata classified as strong enough plant in the high-light condition. CFR of M. peltata was not significantly different with CFR of M. micrantha in the shade of $90 \%$ and CFR of $I$. batatas in 55\% shading. But overall, CFR of M. peltata was between $M$. micrantha and I. batatas.

Relative growth rate of $M$. micrantha reached the highest value, followed by M. peltata and I. batatas gained the lowest. The RGR of M. micrantha was high at the $0 \%$ shading, which was influenced by NAR. Leaf weight ratio is the proportion of biomass allocated to the leaves. M. micrantha allocated a smaller proportion of biomass for leaves synthess, but had very high NAR indicating a very high physiological contribution to RGR (Long et al. 2004). This was supported by high content of nitrogen and high PNUE, so physiological $M$. micrantha was superior to $M$. peltata. The high RGR enables the plants to grow rapidly and invasively to occupy space and gain resources (James and Drenovsky 2007). NAR of $M$. micrantha reached a high value when compared with the other two species of plants. The high of NAR also indicate rate increase of plant's biomass per leaf area unit per time unit. The high of NAR are followed by the high of RGR. Therefore, NAR is a physiological index that contributes to the high values of RGR. NAR variations determine the variations of RGR (Shipley 2006).

High nitrogen content of the leaf per leaf area unit will affect the increase rate of biomass per time unit, the amount of $\mathrm{CO}_{2}$ tied up and used for photosynthesis, as well as determine the efficiency of nitrogen use for photosynthesis. The increasing supply of nitrogen causes the increase of chlorophyll content, the rate increase of photosynthesis, and biomass (Feijuan and Cheng 2012).
The photosynthetics nitrogen use efficiency determined how efficient the availablity of nitrogen used for photosynthesis. At the shade of $0 \%$, the full light exposure which means pretty high light stress. Therefore, plants must be able to utilize its resources to maintain photosynthesis, their growth rate, and their nitrogen allocation. The high values of PNUE indicate that the small amount of nitrogen is able to influence the process of photosynthesis, and is also able to form the plant's biomass, especially the leaves (McDowell 2002).

Spesific leaf area (SLA) of I. batatas in the $55 \%$ shade reached the highest values when compared to SLA of $M$. peltata and M. micrantha. However despite this high value of SLA, it gave a very low RGR, most likely because this plant accumulated food reserve as tubers, preventing it from productive utilisation and infact increase the rate of respiration. The change of SLA results in changes of the leaves' ability to generate the leaves' photosynthate (Durand and Goldstein 2001; Salehian and Eshagi 2012).

Three species of plants showed the lowest values (such as CFR, RGR, LWR, LAR, NAR, and PNUE parameters) in the shade net of $90 \%$. The condition was so bad for most species and tended to kill species used in this experiment. Infact only M. peltata that still survive.

In the preliminary of work it was planned to utilise plant cutting of $M$. peltata to carry out the experiment. Despite a great effort to grow $M$. peltata stem cuttings failed to grow. Stem cuttings with different length, grown in the green house (high humidity), put in horizontal fashion, different physiological age, the use of chemicals to stimulate root inition all of them failed to grow. The cuttings turned brownish, later on blacken and finaly dead and rotted. Some cuttings grew $1.2 \%$ when wrapped in plastic, $0.7 \%$ when layd horizontally, and about $0.8 \%$ when kept under green house condition. It seemed require a high humidity, but not from the preliminary study, we decided to use the seeds for plant propagation which was easily germinate. Therefore, in this experiment we used the seedlings from the seeds.

Propagations of $M$. peltata by seeds has been successfully carried out. M. peltata seeds were separated from the fruit capsules of $M$. peltata were selected. The successful percentage of the propagation of M. peltata seed is much better (the viability percentage is $100 \%$ ) compared with stem cutting. $M$. peltata successfully grown from seeds was due to the supporting structures of the seeds. The structure of $M$. peltata seeds was hairy and strong, and it was very suitable to be distributed through water.

The mechanism of $M$. peltata invasion seems due to its ability to response to a new open environment, with plenty of light, by changing LAR, through a greater resource allocation for leaf synthesis. Although the CFR was lower than that $M$. micrantha (infact the values were relatively high). It showed a very low RGR for all species, but displayed an interesting differences, i.e. M. micrantha showed high the NAR, but low the 
LAR, meaning that $M$. micrantha has a high contribution to its the RGR, while M. peltata has a high the LAR and low the NAR, meaning that while the physiological index was lower than that of M.micrantha, but it has higher the LAR, i.e. allocating more photosynthate for leaves synthesis.

Physiological character of invasive alien species (IAS) is known to have the growth rate, the ability to capture resources, and the high efficiency (Feng et al. 2007). Some variables of M. peltata was not significantly different from $M$. micrantha and $I$. batatas. Although, there was a tendency of $M$. peltata to produce a response between $M$. micrantha and I. batatas. The degree of similarity was almost $55 \%$ which showed that M. peltata and M. micrantha had high similar characters.

The carbon fixation rate, RGR, NAR, and PNUE in the shade of $90 \%$ were variables to support $M$. peltata as a typical IAS. M. peltata demonstrates its ability to maintain its several physiological processes in a state of less energy. CFR of $M$. peltata showed high. The RGR, NAR, and PNUE of $M$. peltata reached the highest in this shade compared to M. micrantha and I. batatas. The high of CFR mean the rate of $\mathrm{CO}_{2}$ binding of photosynthesis is also high. RGR was growth rate that seems to be influenced by net assimilation rate. It means that the RGR was influenced by the amount of $\mathrm{CO}_{2}$ used for photosynthesis purposes. The impacts of high RGR and NAR were also followed by high of PNUE. The high used of nitrogen in photosynthesis makes $M$. peltata more efficient. It was efficient due to the high shade condition, $M$. peltata can still take advantage of its little resources to proceed photosynthesis. The CFR, RGR, NAR, and PNUE are all factors associated with the physiological processes. The physiological factor of $M$. peltata showed the highest in low light stress conditions indicates that $M$. peltata belongs to the plant species that was resistant to low-light stress. Plant species that was resistant to high shade stress (low light) indicates that the life range of $M$. peltata is very wide living. The ability to live on a wide range (from high, moderate to low shades) was included in IAS group (Nagel and Griffin 2004; Poorter 2010).

The physiological characters such as CFR, RGR, LAR, and PNUE of M. peltata showed higher values. These results indicated that physiological characters that are associated with RGR and supporting the invasiveness of $M$. peltata were related to resource allocation to leaf biosynthesis and relatively efficient nitrogen use for photosynthesis. It was rather different from $M$. micrantha with higher value of NAR indicating a high physiological index, with relatively high CFR and RGR. The NAR indicates a physiological index, a greater value indicates a greater physiological contribution to the growth of the plant. This is in line with finding reported by Deng et al. (2004), who indicated the important physiological contribution to its invasiveness. The correlation between LAR with LWR and LAR with SLA showed that leaf biomass allocation and leaf area per weight leaf to contribute more to the high ratio of leaf area.

$M$. peltata had a comprehensive range of life, starting from the low to high shades (the shades of $0 \%, 55 \%$, and $90 \%$ ). This capability was another factor contributing to the success of $M$. peltata to survive in various light conditions.

M. peltata had similar physiological characters with $M$. micrantha based on the overall observed variables. These were indicated that $M$. peltata had some characters of IAS like M. micrantha with degree of similarity was $55 \%$.

It can be concluded that $M$. peltata acclimatized to the low light intensity (shade 90\%) were able to survive and when they grown in the shade of $55 \%$ and $0 \%$ able to improve the quality of leaf in the form of PNUE like $M$. micrantha and also able to use a greater leaf area to support RGR. These conditions provide opportunities M. peltata to become invasive.

\section{Acknowledgements}

The authors would like to thank SEAMEO BIOTROP (through Dr. Sri Sudarmiyati Tjitrosoedirdjo) and Yayasan Toyota \& Astra which had been generously funding this research. Thank also to Wildife Conservation Society which had provided facilities during this research activities.

\section{References}

Deng X et al. 2004. Gas exchange characteristics of the invasive species Mikania micrantha and its indigenous congener M. cordata (Asteraceae) in South China. Bot Bull Acad Sinica 45:213-220.

Durand LZ, Goldstein G. 2001. Photosynthesis, photoinhibition, and nitrogen use efficiency in native and Invasive tree ferns in Hawaii. Oecologia 126:345354.

Feijuan W, Cheng Z. 2012. Effects of nitrogen and light intensity on tomato (Lycopersicon esculentum Mill) production under soil water control. Africa J Agric Res 7:4408-4415.

Feng $\mathrm{Y}$ et al. 2007. Biomass allocation, morphology, and photosynthesis of invasive and noninvasive exotic species grown at four irradiance levels. Acta Oecologica 31:40-47.

Irianto R, Tjitrosoedirdjo S. 2010. Invasi on of Merremia peltata (L) Merr., Convolvulaceae in Taman Nasional Bukit Barisan Selatan, Indonesia. J Gulma dan Tumbuhan Invasif Tropika 1: 65-70. (in Indonesian).

James JJ, Drenovsky RE. 2007. A basis for relative growth rate differences between native and invasive forb seedlings. Rangeland Ecol Manage 60:395-400.

Long SP et al. 2004. Rising atmospheric carbon dioxide: Plants FACE the future. Annu Rev Plant Biol 55:591628.

Master J et al. 2013. Ecological impact of Merremia peltata (L.) Merrill invasion plant diversity at Bukit Barisan Selatan National Park. Biotropia 20: 29-37.

Matzek V. 2011. Superior performance and nutrient use efficiency of invasive plants over non-invasive congeners in a resource-limited environment (report). Biol Invasion 13:3005-3014. 
McDowell SCL. 2002. Photosynthetic characteristics of invasive and noninvasive species of Rubus (Rosaceae). Am J Bot 89:1431-1438.

Nagel JM, Griffin KL. 2004. Can gas exchange characteristic help explain the invasive success of Lythrum salicaria. Biol Invasions 6:101-111.

Poorter L. 2010. Growth resposes of 15 rain forest tree species to a light gradient: the relative importance of morphological and physiological traits. Functional Ecol 13:396-410.

Rodosevich S et al. 1997. Weed ecology, implications for management second edition. New York: J Wiley and Sons.
Salehian H, Eshagi O. 2012. Growth analysis some weed species. Int J Agric Crop Sci 4:730-734.

Shipley B. 2006. Net assimilation rate, specific leaf area, and leaf mass ratio: which is most closely correlated with relative growth rate? A meta-analysis. Functional Ecol 20:565-574.

Taiz L, Zeiger E. 2010. Plant Physiology Fifth Edition. Massachusetts. Sinauer Associates, Inc.

Tjitrosoedirdjo S. 2010. Konsep Gulma dan Tumbuhan Invasif. J Gulma dan Tumbuhan Invasif Tropika 1:89100. 